\title{
THE IMPACT OF ZEROVALENT COBALT NANOPARTICLE ON PHOTOSYNTHESIS - RELATED GENES EXPRESSION IN SOYBEAN LEAVES Glycine $\max$ (L.) Merr. (DT26)
}

\author{
Luu Thi Tam ${ }^{1}$, Hoang Thi Minh Hien ${ }^{1}$, Hoang Thi Lan Anh', \\ Phan Hoang Tuan', Dang Diem Hong ${ }^{1,3, *}$ \\ ${ }^{1}$ Institute of Biotechnology, VAST, Vietnam \\ ${ }^{2}$ University of Science, University of Thai Nguyen, Thai Nguyen, Vietnam \\ ${ }^{3}$ Graduate University of Science and Technology, VAST, Vietnam
}

Received 8 Juanuary, accepted 20 March 2019

\begin{abstract}
Photosynthesis is an important physiological process in plants. It plays a crucial role in plant growth and development. In this study, we investigated the impact of zerovalent cobalt nanoparticles on the photosynthesis and expressing of gene involving in this process in leave of soybean Glycine $\max (\mathrm{L}$.$) Merr "DT26" at different growth stages. The results showed that$ treatment of zerovalent cobalt nanoparticles made in Vietnam and USA (with two doses of 0.17 and $16.67 \mathrm{mg} / \mathrm{kg}$ of soybean seed) enhanced the photosynthesis of soybean by increasing the content of chlorophyll a and the ratio of $\mathrm{Fv} / \mathrm{Fm}$ compared with the control (without treatment of zerovalent cobalt nanoparticles). These values tended to increase and reached the maximum value at 40 days and then decreased in at 70 days. The expression level of photosynthesis-related genes of soybean leaves also changed depending on the soybean's growth stage and concentration of zerovalent cobalt nanoparticles being treated. The genes psaA, Lhca, psa $\mathrm{B}$, Cytb6f (belonging to photosystem I) and $p s b \mathrm{~A}, p s b \mathrm{~B}, p s b \mathrm{C}, p s b \mathrm{D}, p s b \mathrm{E}$ (belonging to photosystem II) in the experimental fomulas were higher expressed than that in control group at 20 and 70 days. However, at 40 days, the expression levels of these genes were significantly different. Obtained results supplied the basis for understanding the active mechanism of the above genes to control/regulates photosynthetic activity of plants with and without the presence of zerovalent cobalt nanoparticles as well as under stress conditions.
\end{abstract}

Keywords: Glycine max, cobalt nanoparticles, Cytb6f, Fv/Fm, Lhca, photosynthesis, psaA, psaB, psbA-E, genes.

Citation: Luu Thi Tam, Hoang Thi Minh Hien, Hoang Thi Lan Anh, Phan Hoang Tuan, Dang Diem Hong, 2019. The impact of zerovalent cobalt nanoparticle on photosynthesis - related genes expression in soybean leaves Glycine max (L.) Merr. (DT26). Tap chi Sinh hoc, 41(1): 141-152. https://doi.org/10.15625/0866-7160/v41n1.13540.

*Corresponding author email: ddhong60vn@yahoo.com/ddhong@ibt.ac.vn

(O2019 Vietnam Academy of Science and Technology (VAST) 


\title{
TÁC ĐỘNG CỦA HẠT NANO COBALT HÓA TRI 0 LÊN MỨC ĐỘ BIỂU HIẸN CỦA MỘT SỐ GEN CHÍNH LIÊN QUAN ĐẾN HOẠT TÍNH QUANG HợP Ở LÁ CÂY ĐẬU TƯONG Glycine max (L.) Merr. (DT26)
}

\author{
Lưu Thị Tâm¹, Hoàng Thị Minh Hiền ${ }^{1}$, Hoàng Thị Lan Anh', \\ Phan Hoàng Tuấn ${ }^{2}$, Đặng Diễm Hồng ${ }^{1,3 ; *}$ \\ ${ }^{1}$ Viện Công nghệ sinh học, Viện Hàn lâm Khoa học và Công nghệ Việt Nam, Việt Nam \\ ${ }^{2}$ Trường Đại học Khoa học, Đại học Thái Nguyên, Thái Nguyên, Việt Nam \\ ${ }^{3}$ Học Viện Khoa học và Công nghệ, Viện Hàn lâm Khoa học và Công nghệ Việt Nam, Việt Nam
}

Ngày nhận bài 8-1-2019, ngày chấp nhận 20-3-2019

\section{TÓM TÁT}

Quang hợp là một quá trình sinh lý quan trọng và là cơ sở của sự sinh trưởng và phát triển của thực vật. Trong nghiên cứu này, chúng tôi đã đánh giá tác động của hạt nano cobalt hóa trị 0 lên quang hợp và mức độ biểu hiện của các gen chính liên quan đến quang hợp của lá cây đậu tương Glycine max (L.) Merr. 'DT26' ở các giai đoạn sinh trưởng khác nhau. Kết quả thu được cho thấy hạt nano cobalt (với 2 mức liều 0,17 và $16,67 \mathrm{mg} / \mathrm{kg}$ hạt do Việt Nam và Mỹ sản xuất) có tác động tích cực lên quang hợp của lá đậu tương thông qua tăng hàm lượng chlorophyll a và hiệu suất quang hóa cực đại $(\mathrm{Fv} / \mathrm{Fm})$ so với lô đối chứng. Các giá trị này có xu hướng tăng dần và đạt giá trị cực đại tại thời điểm 40 ngày, sau đó giảm dần ở thời điểm 70 ngày. Mức độ biểu hiện của các gen liên quan đến hoạt tính quang hợp của lá đậu tương cũng thay đổi theo thời gian sinh trưởng và nồng độ cobalt xử lý. Các gen thuộc quang hệ $\mathrm{I}(p s a \mathrm{~A}, L h c a, p s a \mathrm{~B})$, quang hệ 2 ( $p s b \mathrm{~A}, p s b \mathrm{~B}, p s b \mathrm{C}, p s b \mathrm{D}, p s b \mathrm{E})$ và cytochrome $\mathrm{B}_{6} \mathrm{~F}$ (Cytb6f) ở lô thí nghiệm đều có mức độ biểu hiện cao hơn so với lô đối chứng tại thời điểm 20 và 70 ngày. Tuy nhiên, tại thời điểm 40 ngày, mức độ biểu hiện của các gen này lại có sự khác biệt đáng kể. Kết quả nghiên cứu là cơ sở để hiểu biết về chức năng và cơ chế điều hòa của các gen nêu trên nhằm cải thiện khả năng quang hợp của thực vật dưới điều kiện có và không có mặt hạt colbalt hóa trị 0 cũng như ở những điều kiện bất lợi.

Từ khóa: Glycine max, gen $p s a \mathrm{~A}$, Lhca, $p s a \mathrm{~B}$, Cytb6f, $p s b \mathrm{~A}-\mathrm{E}, \mathrm{Fv} / \mathrm{Fm}$, nano cobalt, quang hợp.

*Địa chỉ liên hệ email: ddhong60vn@yahoo.com/ddhong@ibt.ac.vn

\section{MỞ ĐẦU}

Đậu tương, một cây trồng kinh tế quan trọng trên thế giới, là nguồn cung cấp protein và dầu thực vật chủ lực. Sản lượng và chất lượng của đậu tương chịu ảnh hưởng nhiều bởi điểu kiện môi trường bất lợi, kể cả tác nhân sinh học và phi sinh học. Việc sử dụng các phương pháp hiện đại như công nghệ nano để tăng năng suất cây đậu tương đang là hướng đi tiềm năng. Các hạt nano (sắt, đồng, mangan, kẽm, cobalt, selen... và các dạng oxit của nó) thường được sử dụng như một chất kích thích sinh trưởng thực vật và vi dinh dưỡng. Uu điểm của chúng là có kích thước nhỏ, diện tích bề mặt lớn, dễ hấp thu và nồng độ sử dụng thấp, có khả năng kích hoạt các quá trình trao đổi chất trong cơ thể động thực vật. Đối với cây họ đậu, cobalt đóng một vai trò thiết yếu trong sinh trưởng phát triển của cây bằng cách điều chỉnh việc sử dụng nước và giảm tốc độ thoát hơi nước của cây, đặc biệt là cho sự hình thành nốt sần và quá trình cố định nitơ (DalCorso et al., 2014). Nó là một yếu tố thiết 
yếu để tổng hợp các enzyme và coenzyme khác nhau như vitamin $\mathrm{B}_{12}$ (cyanocobalamin), cần thiết cho dinh dưỡng của người và động vật (Collins \& Kinsela, 2011). Gad et al. (2013) đã công bố sản lượng đậu tương tăng 42,5\% khi cây được xử lý với dung dịch cobalt ở nồng độ $12 \mathrm{mg} / \mathrm{L}$. Cobalt đã được chứng minh có ảnh hưởng đến tăng trưởng và trao đổi chất của thực vật ở các mức độ khác nhau tùy thuộc vào nồng độ và trạng thái của chúng. Jayakumar (2009) đã chỉ ra năng suất đậu tương chỉ tăng khi bổ sung cobalt ở nồng độ thấp $(50 \mathrm{mg}$ cobalt $/ \mathrm{kg}$ đât). Khi xử lý ở nồng độ cobalt cao (100-250 mg/ kg đất) lại làm giảm đáng kể năng suất đậu tương.

Quang hợp ở thực vật là quá trình hấp thu và chuyển đồi năng lượng ánh sáng mặt trời thành năng lượng liên kết hóa học được tích lũy dưới dạng các hợp chất hữu cơ nhờ bộ máy quang hợp (Chia \& He, 1999). Hiệu quả của quá trình quang hợp phụ thuộc vào khả năng hấp thụ, vận chuyển năng lượng ánh sáng về tâm phản ứng của quang hệ II (PSII) và hiệu suất chuyển đổi năng lượng ánh sáng mặt trời thành sinh khối cây trồng. Một số nghiên cứu cũng chứng minh rằng các gen liên quan với hệ thống quang hợp (quang hệ I - PSI và quang hệ II - PSII) rất nhạy cảm với môi trường bất lợi như hạn, mặn (Chaves et al., 2009), ánh sáng và nhiệt độ cao (Murchie et al., 2005). Các protein liên quan đến cấu trúc và chức năng của quá trình quang hợp cũng bị ức chế do điều kiện môi trường bất lợi về nhiệt gây ra (Ahsan et al., 2010). Các yếu tố môi trường bất lợi làm chậm quá trình quang hợp ở thực vật thông qua việc thay đổi cấu trúc lục lạp và giảm hàm lượng sắc tố quang hợp. Năng lượng ánh sáng hấp thụ bởi các sắc tô quang hợp như chlorophyll không được sử dụng hiệu quả bởi các hệ thống PSI và PSII dẫn đến hiệu suất quang hợp thấp và làm giảm năng suất của thực vật.

Ở Việt Nam, một số nghiên cứu về ảnh hưởng của hạt nano cobalt lên khả năng nảy mầm, kéo dài rễ, sinh trưởng, một số thông số về quang hợp và hoạt tính của các enzyme chống ôxy hóa và năng suất của cây đậu tương đã được thực hiện (Ngo et al., 2014; Trần Mỹ Linh và nnk., 2018 ; Phan Hoàng
Tuấn và nnk., 2018a, b). Tuy nhiên, các nghiên cứu về sự biểu hiện của một số gen chính liên quan đến quang hợp ở lá cây đậu tương dưới tác động của các hạt nano cobalt hoàn toàn chưa được thực hiện. Để góp phần lý giải tác động tích cực của hạt nano cobalt lên việc tăng năng suất của cây đậu tương thông qua tăng hoạt động quang hợp, chúng tôi đã tiến hành đánh giá mức độ biểu hiện của một số gen mã hóa cho các protein nằm trong trung tâm phản ứng của PSI và PSII, phức hợp thu nhận ánh sáng và chuỗi vận chuyển điện tử trong mạch vẫn chuyển quang hợp như psa $\mathrm{A}, p s a \mathrm{~B}, p s b \mathrm{~A}, p s b \mathrm{~B}, p s b \mathrm{C}$, $p s b \mathrm{D}, p s b \mathrm{E}, C y t$ b6f và Lhca của giống đậu tương DT26 ở các giai đoạn sinh trưởng khác nhau trong điều kiện có và không có mặt của hạt nano cobalt hóa trị 0 .

\section{VậT LIỆU VÀ PHƯƠNG PHÁP}

Giống đậu tương DT26 (Glycine max (L.) Merr. 'DT26') do Trung tâm Nghiên cứu và Phát triển đậu đỗ, Viện Khoa học Nông nghiệp Việt Nam cung cấp.

\section{Bố trí thí nghiệm}

Thí nghiệm được tiến hành với 5 công thức: Đối chứng (ký hiệu ĐC), xử lý bằng nước RO; thí nghiệm-xử lý với hạt nano cobalt do Việt Nam (VN) và Mỹ (USA) chế tạo với 2 liều là 0,17 và $16,67 \mathrm{mg} / \mathrm{kg}$ hạt tương ứng với nồng độ kích thích (KTVN và KTUSA) và ức chế (UCVN và UCUSA) như đã mô tả chi tiết trong công bố Phan Hoàng Tuấn và nnk. (2018a). Mỗi công thức lặp lại 5 lần.

Tại thời điểm 20, 40 và 70 ngày sau gieo, tiến hành thu các mẫu lá ở lô đối chứng và lô thí nghiệm được xử lý với hạt nano cobalt hóa trị 0 ở các nồng độ khác nhau. Các mẫu lá tươi sau khi thu được giữ ở (-) $20^{\circ} \mathrm{C}$ cho đến khi tiến hành thí nghiệm (Phan Hoàng Tuấn và nnk., 2018a).

\section{Xác định hàm lượng chlorophyll a ở lá đậu tương}

Lá đậu tương non hoàn chỉnh nhất thu tại các thời điểm 20,40 và 70 ngày sau gieo được tách chiết chlorophyll. Qui trình tách chiết chlorophyll được mô tả chi tiết theo công bố của Phan Hoàng Tuấn và nnk. (2018a). 
Đo huỳnh quang chlorophyll a hấp thụ ở bước sóng $680 \mathrm{~nm}$

Huỳnh quang chlorophyll a được xác định tại bước sóng $680 \mathrm{~nm}$ thuộc tâm phản ứng của hệ PSII (P680 nm) bằng máy chlorophyll fluorometer OS-30 (do hãng ADC (Anh) cung cấp) theo mô tả của Nguyễn Văn Mã và nnk. (2013). Điều kiện đo cụ thể như mô tả trong công bố của Phan Hoàng Tuấn và nnk. (2018a). Hiệu suất lượng tử quang hóa cực đại đặc trưng cho phần năng lượng ánh sáng hấp thụ bằng PSII được sử dụng tối đa trong phản ứng quang hóa được thể hiện bằng tỷ lệ $F v / F m$ vói $F v=F m-F o$. Trong đó, $F m$ - huỳnh quang cực đại, $F o$ - huỳnh quang ổn định.

\section{Phương pháp tách chiết RNA tổng số}

RNA tổng số của lá đậu tương DT26 được tách chiết bằng kít RNAiso plus (Takara, Tokyo, Nhật Bản) theo hướng dẫn của nhà sản xuất.

\section{Tổng hợp cDNA từ khuôn RNA tổng số}

cDNA được tổng hợp trên khuôn RNA sử dụng kít RevertAid First Strand cDNA (Singarpore), thực hiện theo hướng dẫn của nhà sản xuất. Lượng RNA làm khuôn mẫu cho một phản ứng tổng hợp cDNA là $1 \mu \mathrm{g}$.

Bảng 1 . Trình tự cặp mồi đặc hiệu để nhân các gen biểu hiện liên quan đến hoạt tính quang hợp ở cây đậu tương DT26 [Nguồn: Teixeira et al. (2016)]

\begin{tabular}{|c|l|l|l|c|l|l|}
\hline TT & \multicolumn{1}{|c|}{ Gen } & \multicolumn{1}{|c|}{ ID gen } & Locus tag & $\begin{array}{c}\text { Kích } \\
\text { thước } \\
\text { dự đoán } \\
\text { (bp) }\end{array}$ & \multicolumn{1}{|c|}{ Mồi xuôi (F) } & Mồi ngược (R) \\
\hline 1 & Lhca & 100815789 & $\begin{array}{l}\text { Glyma } \\
14 \mathrm{~g} 008000\end{array}$ & 155 & $\begin{array}{l}\text { ACCCATGGCACAAC } \\
\text { AACA }\end{array}$ & $\begin{array}{l}\text { ACAGCACAGCGATAC } \\
\text { CAAC }\end{array}$ \\
\hline 2 & $p s a \mathrm{~A}$ & 3989266 & GlmaCp011 & 149 & $\begin{array}{l}\text { AGCAACTCCCTTTT } \\
\text { TCACC }\end{array}$ & $\begin{array}{l}\text { GACCCGCTATCAAGA } \\
\text { AAAGAAT }\end{array}$ \\
\hline 3 & $p s a \mathrm{~B}$ & 3989267 & GlmaCp012 & 180 & $\begin{array}{l}\text { TGGTGTTTATCAGT } \\
\text { GGTGGT }\end{array}$ & $\begin{array}{l}\text { TGATGATTGAGGCGG } \\
\text { GATT }\end{array}$ \\
\hline 4 & $p s b \mathrm{~A}$ & 3989259 & GlmaCp001 & 184 & $\begin{array}{l}\text { GCAAACCTATAGCC } \\
\text { GCAGA }\end{array}$ & $\begin{array}{l}\text { GGATGGTTTGGTGTT } \\
\text { TTGATGA }\end{array}$ \\
\hline 5 & $p s b \mathrm{~B}$ & 3989323 & GlmaCp047 & 101 & $\begin{array}{l}\text { CCCTCTGACCCTGT } \\
\text { TCTT }\end{array}$ & $\begin{array}{l}\text { ATATTCCAACCGCCC } \\
\text { CAC }\end{array}$ \\
\hline 6 & $p s b \mathrm{C}$ & 3989283 & GlmaCp015 & 119 & $\begin{array}{l}\text { CCTAGTAGTTTGCC } \\
\text { GGAT }\end{array}$ & $\begin{array}{l}\text { CACGTGGAAACGCTC } \\
\text { TTTA }\end{array}$ \\
\hline 7 & $p s b \mathrm{D}$ & 3989284 & GlmaCp016 & 130 & $\begin{array}{l}\text { AACGAAGTCATAGG } \\
\text { CACG }\end{array}$ & $\begin{array}{l}\text { CTTTGGGGTTGCTTTT } \\
\text { TCC }\end{array}$ \\
\hline 8 & $p s b \mathrm{E}$ & 3989313 & GlmaCp037 & 105 & $\begin{array}{l}\text { AATTCCTTGTCGGC } \\
\text { TCTCTG }\end{array}$ & $\begin{array}{l}\text { TCCCTATTCATTGCAG } \\
\text { GTTGG }\end{array}$ \\
\hline 9 & Cyt $\mathrm{b} 6 \mathrm{f}$ & 3989327 & GlmaCp051 & 169 & $\begin{array}{l}\text { CGTCCCTCTGTTGT } \\
\text { CATGT }\end{array}$ & $\begin{array}{l}\text { GGAGAGGTGATGGTG } \\
\text { AAAAGTT }\end{array}$ \\
\hline 10 & $\beta-a c t i n$ & CA937380 & $\begin{array}{l}\text { Glyma } 18 \mathrm{~g} \\
52780\end{array}$ & 152 & $\begin{array}{l}\text { GATCTTGCTGGTCG } \\
\text { TGATCT }\end{array}$ & $\begin{array}{l}\text { GTCTCCAACTCTTGCT } \\
\text { CATAGTC }\end{array}$ \\
\hline
\end{tabular}

RT-PCR bán định lượng khuếch đại các gen liên quan đến hoạt tính quang hợp ở cây đậu tương DT26

RT-PCR (Reverse transcription polymerase chain reaction) bán định lượng được thực hiện với khuôn là $\mathrm{cDNA}$ được tổng hợp từ RNA của các mẫu lá đậu tương thu ở các công thức đối chứng và thí nghiệm tại các thời điểm 20, 40 và 70 ngày. Các cặp mồi đặc hiệu cho các gen chính liên quan đển hoạt tính quang hợp như $p s b \mathrm{~A}, p s b \mathrm{~B}, p s b \mathrm{C}$, $p s b \mathrm{D}, p s b \mathrm{E}, p s a \mathrm{~A}, p s a \mathrm{~B}, C y t b 6 \mathrm{f}$ và Lhca được trình bày ở bảng 1 . Phản ứng PCR được thực hiện với tổng thể tích là $20 \mu \mathrm{L}$ bao gồm $1 \mu \mathrm{L}$ cDNA, $10 \mu \mathrm{L}$ Master Mix (10X); $1 \mu \mathrm{L}$ mồi $\mathrm{F}(10 \mathrm{pmol}), 1 \mu \mathrm{L}$ mồi $\mathrm{R}(10 \mathrm{pmol}), 7$ $\mu \mathrm{L} \mathrm{H}_{2} \mathrm{O}$. Chu trình nhiệt được thực hiện như 
sau: Bước 1: $95^{\circ} \mathrm{C}, 5$ phút; bước $2: 95^{\circ} \mathrm{C}, 30$ giây; bước $3: 49^{\circ} \mathrm{C}, 30$ giây (đối với các gen $p s b \mathrm{~A}, p s b \mathrm{C}, p s b \mathrm{D}, p s b \mathrm{E}, p s a \mathrm{~A}, p s a \mathrm{~B})$ và $52^{\circ} \mathrm{C}, 30$ giây (đối với các gen $p s b \mathrm{~B}, C y t$ b6f, Lhca); bước $4: 72^{\circ} \mathrm{C}, 1$ phút 30 giây; bước 5 : Lặp lại 35 chu kỳ từ bước 2 đến bước 4 ; bước $6: 72^{\circ} \mathrm{C}, 5$ phút, bước 7 : Giữ sản phẩm ở $15^{\circ} \mathrm{C}$ cho tới khi sử dụng. Sử dụng $\beta$-actin như là gen tham chiếu để chuẩn hóa số liệu. Điều kiện nhân gen $\beta$-actin là tương tự với từng gen nêu trên. Sản phẩm PCR được kiểm tra bằng điện di trên gel agarose $2 \%$, nhuộm với ethidium bromide, sau đó được chụp ảnh và xử lý bằng phần mềm phân tích Gel pro32 Analyzer.

\section{Xử lý số liệu}

Mức độ biểu hiện của các gen được đánh giá thông qua diện tích và độ đậm nhạt của các băng sau điện di bằng phần mềm phân tích Gel pro32 Analyzer để định lượng gián tiếp hàm lượng của các băng. Tỷ lệ độ đậm băng của các gen $p s a \mathrm{~A}, p s a \mathrm{~B}, p s b \mathrm{~A}-\mathrm{E}, C y t b 6 \mathrm{f}$ và Lhca ở từng thời điểm tại mỗi công thức thí nghiệm sẽ được chuẩn hóa với gen $\beta$-actin tương ứng và so sánh với công thức đối chứng (không được xử lý hạt nano cobalt). Số liệu được trình bày bằng MEAN \pm SEM. Các kết quả thu được được xử lý bằng phần mềm Excel. Sự sai khác giữa các công thức thí

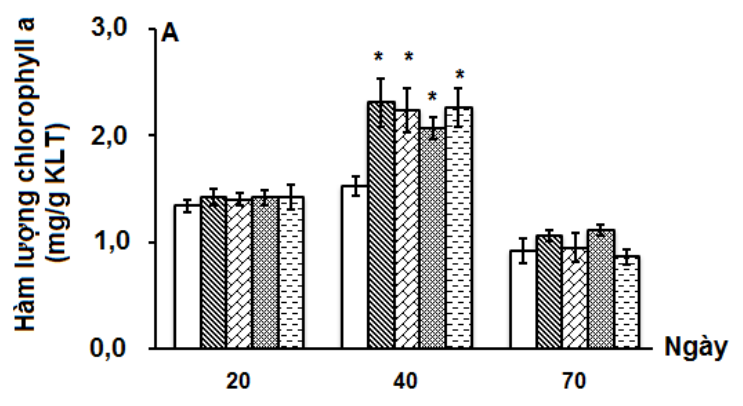

nghiệm được đánh giá bằng phân tích ANOVA một yếu tố với mức ý nghĩa $P$ < 0,05 .

\section{KẾT QUẢ VÀ THẢO LUẬN}

Hàm lượng chlorophyll a và hiệu suất quang hóa cụ̣c đại $(\mathbf{F v} / \mathbf{F m})$ của lá đậu tương ở các giai đoạn sinh trưởng khác nhau dưới tác động của hạt nano cobalt hóa trị 0

Tốc độ quang hợp của thực vật liên quan trực tiếp đển mật độ và kích thước của các ăng ten thu nhận ánh sáng, cụ thể là các phân tử sắc tố chlorophyll (Shao et al., 2014). Khi phân tử chlorophyll a hấp thụ năng lượng ánh sáng, chúng sẽ chuyển từ trạng thái cơ bản lên trạng thái kích thích. Phân tử chlorophyll a ở trạng thái kích thích sẽ mất năng lượng bằng một số quá trình như mất nhiệt, phát huỳnh quang và thực hiện phản ứng quang hóa. Tồng hằng số của các phản ứng nêu trên là không đổi. Nếu coi quá trình mất nhiệt là như nhau ở mọi điều kiện thí nghiệm thì hiệu quả quang hợp của thực vật có thể được đánh giá thông qua huỳnh quang của chlorophyll a trong lá cây. Kết quả về sự thay đổi hàm lượng chlorophyll a và tỷ lệ $\mathrm{Fv} / \mathrm{Fm}$ của cây đậu tương ở các giai đoạn khác nhau dưới tác động của hạt nano cobalt được trình bày trên hình 1.

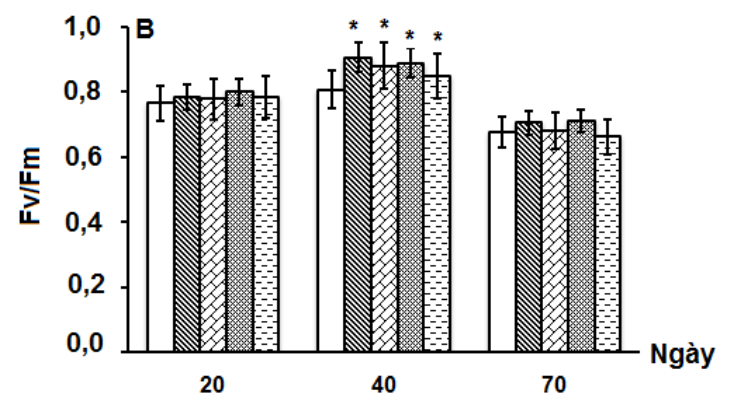

$\square \boxminus C \mathbb{B}$ KTVN $\square U^{\prime C V N}$ KTUSA घƯCUSA

Hình 1. Sự thay đổi hàm lượng chlorophyll a (A) và tỷ lệ Fv/Fm (B) của lá cây đậu tương DT26 ở các giai đoạn sinh trưởng khác nhau khi có và không có mặt hạt nano cobalt. Dấu “*” chỉ sự sai có có ý nghĩa thống kê ở lô thí nghiệm so với lô ĐC $(P<0,05)$

Kết quả chỉ ra trên hình $1 \mathrm{~A}$ đã cho thấy việc xử lý hạt đậu tương DT26 với dung dịch hạt nano cobalt của Việt Nam và Mỹ đều có tác động tích cực lên quang hợp của cây đậu tương thông qua tăng hàm lượng chlorophyll $\mathrm{a}$ so với lô đối chứng. Hàm lượng chlorophyll a 
có xu hướng tăng dần và đạt cực đại ở thời điểm 40 ngày sau gieo. Sau đó, hàm lượng này giảm mạnh khi cây đậu tương chuyển sang giai đoạn sinh trưởng sinh thực (70 ngày sau gieo). Không có sự sai khác có ý nghĩa thống kê sinh học về hàm lượng chlorophyll $\mathrm{a}$ giữa lô $C$ và thí nghiệm ở thời điểm 20 và 70 ngày $(P>0,05)$. Tuy nhiên, sự khác biệt có ý nghĩa thống kê sinh học về hàm lượng chlorophyll a giữa các lô xử lý với hạt nano cobalt so với lô $\mathrm{ĐC}$ được thể hiện rõ rệt tại thời điểm 40 ngày $(P<0,05)$. Điều này có thể do việc xử lý hạt cobalt đã giúp hỗ trợ quá trình tổng hợp chlorophyll và hạn chế sự phân hủy của nó ở trong tối (Abdul Jaleel et al., 1999). Kết quả của chúng tôi cũng tương đồng với công bô của $\mathrm{Ngo}$ et al. (2014) cho thấy hàm lượng chlorophyll của cây đậu tương DT51 tăng khoảng 10\% so với đối chứng khi hạt được xử lý với dung dịch hạt nano cobalt ở nồng độ $0,08 \mathrm{~g} / \mathrm{ha}$.

Tỷ lệ Fv/Fm là một tham số huỳnh quang chlorophyll quan trọng, thể hiện hiệu quả sủ dụng tối đa năng lượng ánh sáng được hấp thụ bởi sắc tố trong phản ứng quang hóa ở PSI và II và được sử dụng như là một chỉ thị để phát hiện sớm những thay đổi về cấu trúc và chức năng của bộ máy quang hợp của thực vật dưới điều kiện sinh lý bình thường và điều kiện bất lợi (Qiu et al., 2013). Sự thay đổi tỷ lệ Fv/Fm của lá cây đậu tương ở các giai đoạn sinh trưởng khác nhau dưới tác động của hạt nano cobalt được chỉ ra ở hình $1 \mathrm{~B}$. Xu hướng thay đổi của hiệu suất quang hóa cực đại cũng tương tự như hàm lượng chlorophyll. Sự sai khác có ý nghĩa thống kê khi so sánh giữa lô ĐC và lô xử lý hạt nano cobalt ở nồng độ $0,17 \mathrm{mg} / \mathrm{kg}$ hạt $(P<0,05)$ tại thời điểm 40 ngày sau gieo. Kết quả này cho thấy xử lý hạt đậu tương với dung dịch nano cobalt đã giúp việc sử dụng năng lượng ánh sáng trong phản ứng quang hóa ở PSII đạt hiệu quả cao hơn dẫn tới tăng tỷ lệ Fv/Fm.

\section{Mức độ biểu hiện của các gen liên quan đến quang hợp ở lá cây đậu tương DT26 dưới tác động của hạt nano cobalt}

Các yếu tố môi trường bất lợi đều ảnh hưởng lớn đến quang hợp. Vì vậy, thực vật luôn có cơ chế tự bảo vệ bằng cách thay đồi mức độ biểu hiện của các gen liên quan đến hoạt động của PSI và PSII để bảo vệ bộ máy quang hợp, làm giảm nhẹ ảnh hưởng của các yếu tố môi trường gây ức chế quang hợp và cân bằng nội môi tế bào (Wang et al., 2014).

Lõi của $\mathrm{PSII}$ gồm 2 protein $\mathrm{D} 1$ và $\mathrm{D} 2$ (được mã hóa bởi gen $p s b \mathrm{~A}$ và $p s b \mathrm{D}$ ) liên kết thành heterodimer nằm ngay giữa trung tâm phản ứng PSII được ký hiệu là phân tử huỳnh quang $\mathrm{P}_{680}$, là chất nhận điện tử sơ cấp trong mạch vận chuyển điện tử quang hợp. Chúng cùng với một số các phân từ sắc tố chlorophyll a, $\beta$-caroten và sắt..., tạo nên tâm phản ứng của PSII. Tất cả được kết nối thành một mạch vận chuyển điện tử $[\mathrm{Mn}] 4$, TyrZ, pheophytin $\mathrm{a}, \mathrm{QA}, \mathrm{QB}$ và nonheme. Trong khi đó, 2 loại protein khác (được mã hóa bởi hai gen $p s b \mathrm{~B}$ và $p s b \mathrm{C}$ ) liên kết mảng với các phân tử chlorophyll và $\beta$-carotene dưới dạng phức hợp thu nhận ánh sáng, CP47 và $\mathrm{CP} 43$ (Barber et al., 1997). Sự thay đổi mức biểu hiện của các gen này sẽ ảnh hưởng đến chức năng quang hợp như hiệu suất lượng tử của quang hợp và thay đổi hoạt tính quang hợp (Luciński \& Jackowski, 2006). PSI (theo sau PSII trong chuỗi vận chuyển điện tử quang hợp), là chất nhận điện tử từ phức hợp cytochrom b6f và chuyển chúng đến ferredoxin để sản xuất các phân tử có hiệu năng cao như NADPH. Sau đó, chúng tiếp tục được sử dụng trong các phản ứng tối để cố định $\mathrm{CO}_{2}$ theo chu trình Calvin Benson. Các thành phần của PSI được mã hóa bởi các gen lục lạp và gen nhân như $p s a \mathrm{~A}, p s a \mathrm{~B}$, Lhca, có chức năng thu nhận ánh sáng và vận chuyển năng lượng được hấp thụ tới lõi của PS II (Berry et al., 2013).

Kết quả về điện di sản phẩm PCR nhân các gen $p s a \mathrm{~A}-\mathrm{B}, p s b \mathrm{~A}-\mathrm{E}, C y t b 6 f$ và Lhca mã hóa cho các protein liên quan đến bộ máy quang hợp ở cây đậu tương DT26 được chỉ ra ở hình 2. Mức độ biểu hiện của các gen nêu trên của lá cây đậu tương DT26 ở các giai đoạn sinh trưởng khác nhau dưới điều kiện có và không có mặt của hạt nano cobalt hóa trị 0 được chỉ ra ở bảng 2 và hình 3 .

Kết quả chỉ ra ở bảng 2 và hình 3 cho thấy khi xử lý hạt nano cobalt của Việt Nam và Mỹ ở cả 2 nồng độ kích thích $(0,17 \mathrm{mg} / \mathrm{kg}$ hạt $)$ và 
ức chế $(16,67 \mathrm{mg} / \mathrm{kg}$ hạt), cả 9 gen liên quan đến hoạt tính quang hợp (thuộc cả PSI và II) đều có xu hướng tăng mức độ biểu hiện (với mức tăng từ 1 đển 1,7 lần tùy từng gen) so với lô $Đ C$ ở giai đoạn 20 và 70 ngày. Tại thời điểm 20 ngày, sự sai khác có ý nghĩa thống kê sinh học ở mức độ biểu hiện của các gen này ở các lô xử lý hạt cobalt nồng độ $16,67 \mathrm{mg} / \mathrm{kg}$ hạt so với ĐC $(P<0,05)$. Tuy nhiên, ở nồng độ xử lý $0,17 \mathrm{mg} / \mathrm{kg}$ hạt thì mức độ sai khác không có ý nghĩa thổng kê $(P>0,05)$. Tại thời điểm 70 ngày, việc xử lý hạt nano cobalt đều làm tăng biểu hiện của các gen liên quan đến hoạt tính quang hợp của cây đậu tương $(P<$ $0,05)$.

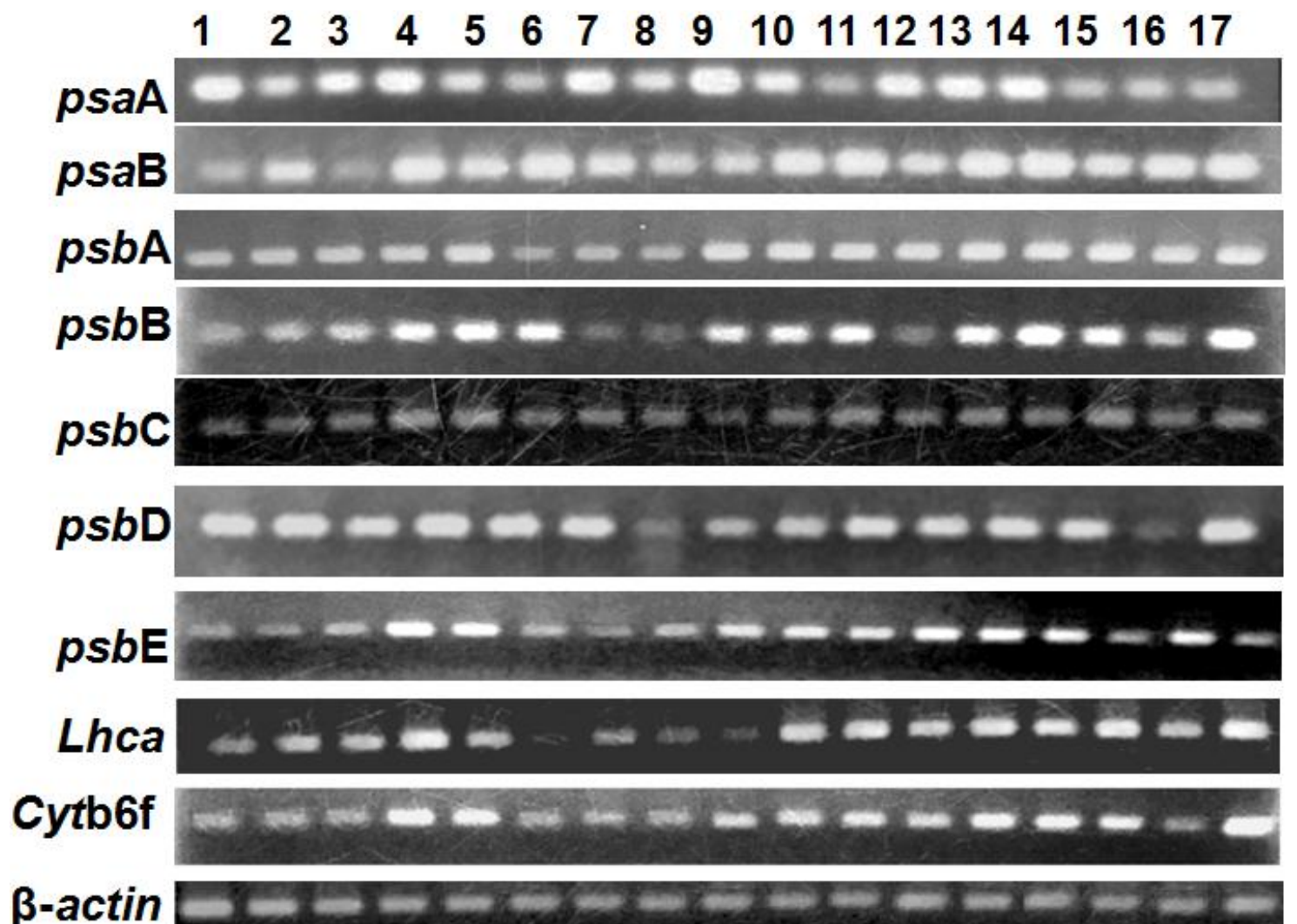

Hình 2. Ảnh điện di nhân gen $p s a \mathrm{~A}-\mathrm{B}, p s b \mathrm{~A}-\mathrm{E}, C y t b 6 f$ và Lhca mã hóa cho các protein liên quan đến bộ máy quang hợp ở cây đậu tương DT26

Giếng 1-17 tương úng với mẫu:
1: ĐC- 20 ngày
6: ĐC- 40 ngày
12: ĐC- 70 ngày
2: KTVN - 20 ngày
8: KTVN - 40 ngày
14: KTVN - 70 ngày
3: KTUSA - 20 ngày
9: KTUSA - 40 ngày
4: U'CVN - 20 ngày
10: U'CVN - 40 ngày
15: KTUSA - 70 ngày
5: UCUSA- 20 ngày
11: ƯCUSA- 40 ngày
16: UCVN - 70 ngày
17: U’CUSA- 70 ngày

Ở giai đoạn 40 ngày, là thời điểm quang hợp của cây đậu tương đạt cực đại, sự biểu hiện của các gen này có sự sai khác rõ rệt. Đối với các gen $L h c a$, psaA (thuộc PSI, có chức năng thu nhận ánh sáng và vận chuyển điện tử), gen cytb6f (thuộc phức hợp cytochrome) và gen $p s b \mathrm{~A}$ (mã hóa cho protein D1 của PSII có chức năng vận chuyển điện tử) có $\mathrm{xu}$ hướng biểu hiện tăng ở lô được xử lý hạt nano cobalt so với lô ĐC (ngoại trừ lô xử lý hạt nano cobalt Mỹ ở nồng độ $16,67 \mathrm{mg} / \mathrm{kg}$ hạt). Như vậy, tại thời điểm quang hợp tăng thì 
mức độ biểu hiện của các gen mã hóa cho các protein liên kết với sắc tố để thu nhận ánh sáng trong PSI cũng tăng, tức là quá trình vận chuyển điện tử trong PSI được tăng cường. Ngược lại, các gen psaB (thuộc PSI, có chức năng vận chuyển điện tử trong mạch vận chuyển điện tử quang hợp), các gen $p s b \mathrm{~B}-\mathrm{E}$ (mã hóa cho protein của tâm phản ứng PSII, có chức năng vận chuyển điện tử trong mạch vận chuyển đện tử quang hợp) lại có mức độ biểu hiện gen giảm so với lổ ĐC. Kết quả này có thể do tốc độ vận chuyển điện tử của protein được mã hóa bởi các gen $p s a \mathrm{~B}, p s b \mathrm{~B}$ $\mathrm{E}$, tham gia vào phản ứng sáng của quá trình quang hợp có xu hướng giảm khi hoạt tính quang hợp của cây tăng.
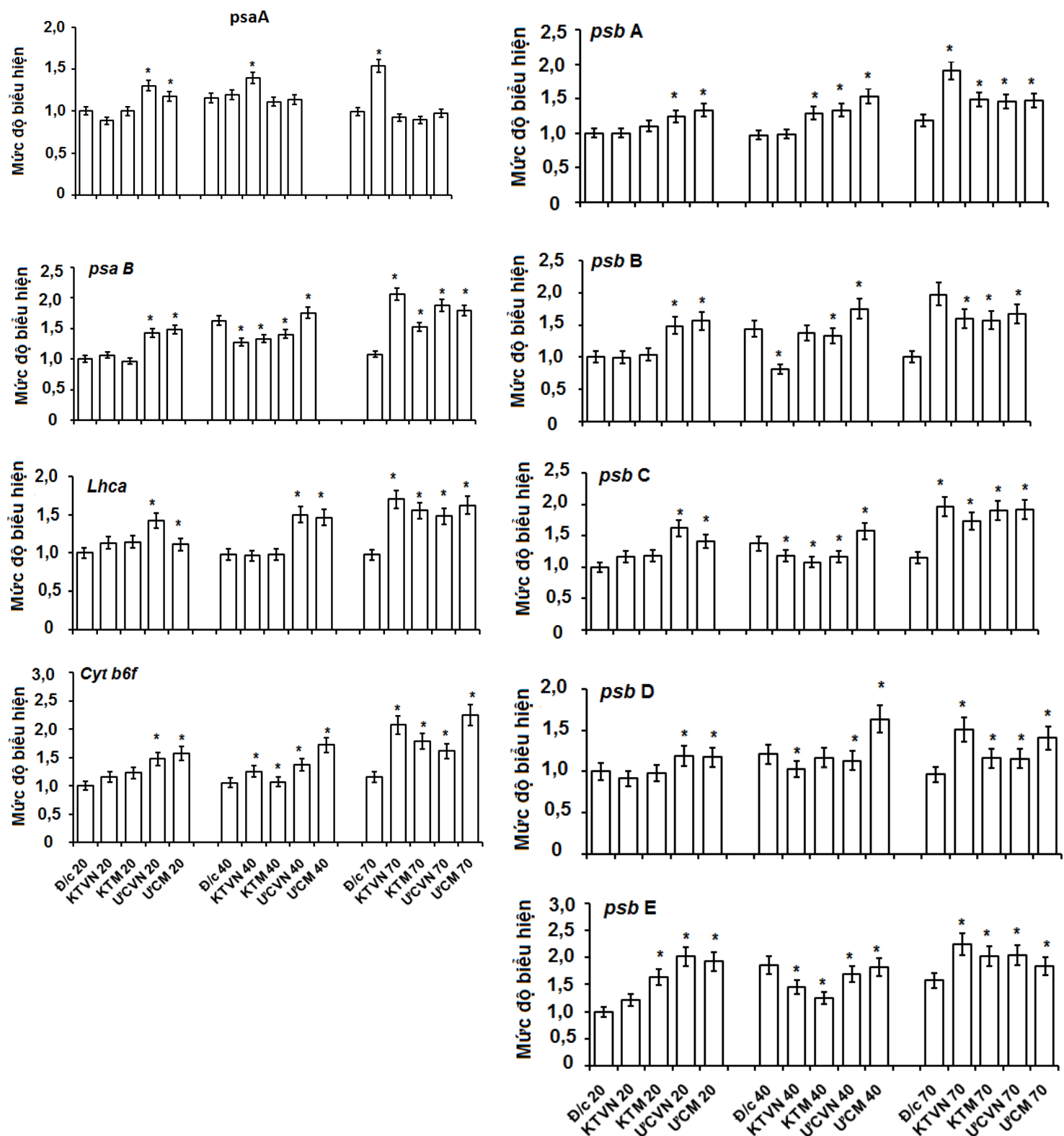

Hình 3. Mức độ biểu hiện của các gen liên quan đến hoạt tính quang hợp của cây đậu tương DT26 ở các giai đoạn khác nhau khi khi có và không có mặt hạt nano cobalt. Dấu “*” chỉ sự sai có có ý nghĩa thống kê ở lô thí nghiệm so với lô ĐC $(P<0,05)$ 
Bảng 2. Mức độ biểu hiện của các gen chính liên quan đến hoạt tính quang hợp ở lá cây đậu tương DT26 ở các giai đoạn sinh trưởng khác nhau

\begin{tabular}{|c|c|c|c|c|c|}
\hline \multirow{2}{*}{ Gen } & \multirow{2}{*}{ Mã hóa protein } & \multirow{2}{*}{ Chức năng } & \multicolumn{3}{|c|}{ Mức độ biếu hiện gen } \\
\hline & & & 20 ngày & 40 ngày & 70 ngày \\
\hline \multicolumn{6}{|c|}{ Quang hệ I } \\
\hline psaA & Apoprotein A1 & Vận chuyển điện tử & + & + & + \\
\hline$p s a \mathrm{~B}$ & Apoprotein A2 & Vận chuyển điện tử & + & - & + \\
\hline Lhca & Protein gắn với sắc tố & Thu nhận ánh sáng & + & + & + \\
\hline \multicolumn{6}{|c|}{ Quang hệ II } \\
\hline$p s b \mathrm{~A}$ & Protein D1 & Vận chuyến điện tử & + & + & + \\
\hline$p s b \mathrm{~B}$ & $\begin{array}{l}\text { Protein của trung tâm } \\
\text { phản ứng } \mathrm{CP} 47\end{array}$ & $\cos ^{2}$ & + & - & + \\
\hline$p s b \mathrm{C}$ & $\begin{array}{l}\text { Protein của trung tâm } \\
\text { phản ứng CP43 }\end{array}$ & $\mathrm{nt}$ & + & - & + \\
\hline$p s b \mathrm{D}$ & Protein D2 & $\mathrm{nt}$ & + & - & + \\
\hline$p s b \mathrm{E}$ & $\begin{array}{l}\text { Tiếu phần } \alpha \text { của } \\
\text { Cytochrome b559 }\end{array}$ & $\mathrm{nt}$ & + & - & + \\
\hline Cyt6f & Protein PET A & $\mathrm{nt}$ & + & + & + \\
\hline
\end{tabular}

Ghi chú: nt: Như trên; dấu (-): Giảm mức độ biểu hiện gen; dấu (+): Tăng mức độ biểu hiện gen ở công thức thí nghiệm so với công thức đối chứng. PET: Photosynthetic electron transport - vận chuyển điện tử quang hợp; Vị trí và chức năng của các gen tham khảo theo công bố của Berry et al. (2013).

Trong cùng một công thức, biểu hiện của các gen liên quan đến quang hợp cũng có xu hướng khác nhau (hình 4).

Ở lô ĐC, mức độ biểu hiện của các gen $p s a \mathrm{~A}, p s a \mathrm{~B}, p s b \mathrm{~A}-\mathrm{E}$ có tương quan chặt với hàm lượng chlorophyll $\mathrm{a}$. Khi hàm lượng chlorophyll a đạt cực đại tại thời điểm 40 ngày, hoạt động của các gen này cũng đạt cao nhất. Ngoại trừ 2 gen Lhca và Cytb6f có xu hướng ổn định trong suốt thời gian sinh trưởng của cây đậu tương. Ở lô xử lý hạt nano cobalt ở nồng độ $0,17 \mathrm{mg} / \mathrm{kg}$ hạt (KTVN và KTUSA), tất cả 9 gen liên quan đến quang hợp đều có mức độ biểu hiện thay đổi không đáng kể giữa thời điểm 20 đến 40 ngày. Tuy nhiên, tại thời điểm 70 ngày, tất cả các gen này đều được tăng cường hoạt động. Có sự khác biệt có ý nghĩa ở mức độ biểu hiện của các gen tại thời điểm 40 và 70 ngày $(P<$ $0,05)$. Khi tăng nồng độ cobalt xử lý $(16,67$ $\mathrm{mg} / \mathrm{kg}$ hạt), sự thay đổi biểu hiện của các gen ở các thời điểm khác nhau là không nhiều và sự sai khác không có ý nghĩa thống kê sinh học $(P>0,05)$. Kêt quả nghiên cứu của chúng tôi cũng cho thấy hiệu quả tác động của hạt nano cobalt của Việt Nam và Mỹ ở cả 2 liều
0,17 và $16,67 \mathrm{mg} / \mathrm{kg}$ hạt là không có sự khác biệt. Ngay cả liều xử lý cao $16,67 \mathrm{mg} / \mathrm{kg}$ hạt đều chưa phát hiện thấy tác động tiêu cực đến bộ máy quang hợp của cây đậu tương DT26.

Một số nghiên cứu trên thế giới cũng cho thấy cobalt ở nồng độ thấp có ảnh hưởng tích cực lên sinh trưởng cũng như tốc độ vận chuyển điện tử trong mạch vận chuyển điện tử quang hợp (Mohanty et al., 1989 ; Ali et al., 2010). Mohanty et al. (1989) đã đưa ra giả thuyêt rằng tác dụng của cobalt lên quang hợp có thể do chúng có vai trò thay đổi chức năng của $\mathrm{Q}_{\mathrm{B}}$ trong mạch vận chuyển điện tử, dẫn đến ảnh hưởng lên hoạt động của quang hợp. El- Sheekh et al. (2003) đã công bố về ảnh hưởng của nồng độ cobalt lên sinh trưởng, hàm lượng sắc tố và mạch vận chuyển điện tử trong quang hợp của 2 loài tảo Monoraphidium minutum và Nitzschia perminuta. Kết quả cho thấy cobalt kích thích sinh trưởng và hàm lượng sắc tố của 2 loài tảo này ở nồng độ thấp $(0,1-0,5$ ppm). Cobalt ảnh hưởng trực tiếp lên phức hợp $\mathrm{P}_{680}$ của mạch vận chuyển điện tử trong PSII. Có sự thay đổi trong việc phân phối năng lượng kích thích có lợi cho hệ thống PSI. Điều này cũng có thể 
dẫn tới sự tăng cường tổng hợp phân tử ATP thông qua quá trình vận chuyển điện tử vòng trong mạch vận chuyển điện tử quang hợp dẫn tới tăng cường/kích thích sự tích lũy carbon vô cơ trong các tế bào sinh trưởng khi nồng độ cobalt thấp. Tuy nhiên, để hiểu rõ hơn cơ chế phân tử của hạt nano cobalt tác động lên hoạt động quang hợp ở cây đậu tương DT26 cần phải có những nghiên cứu sâu hơn nữa ở các sản phẩm mã hóa bởi các gen liên quan đến quang hợp của PSI và PSII nêu trên.
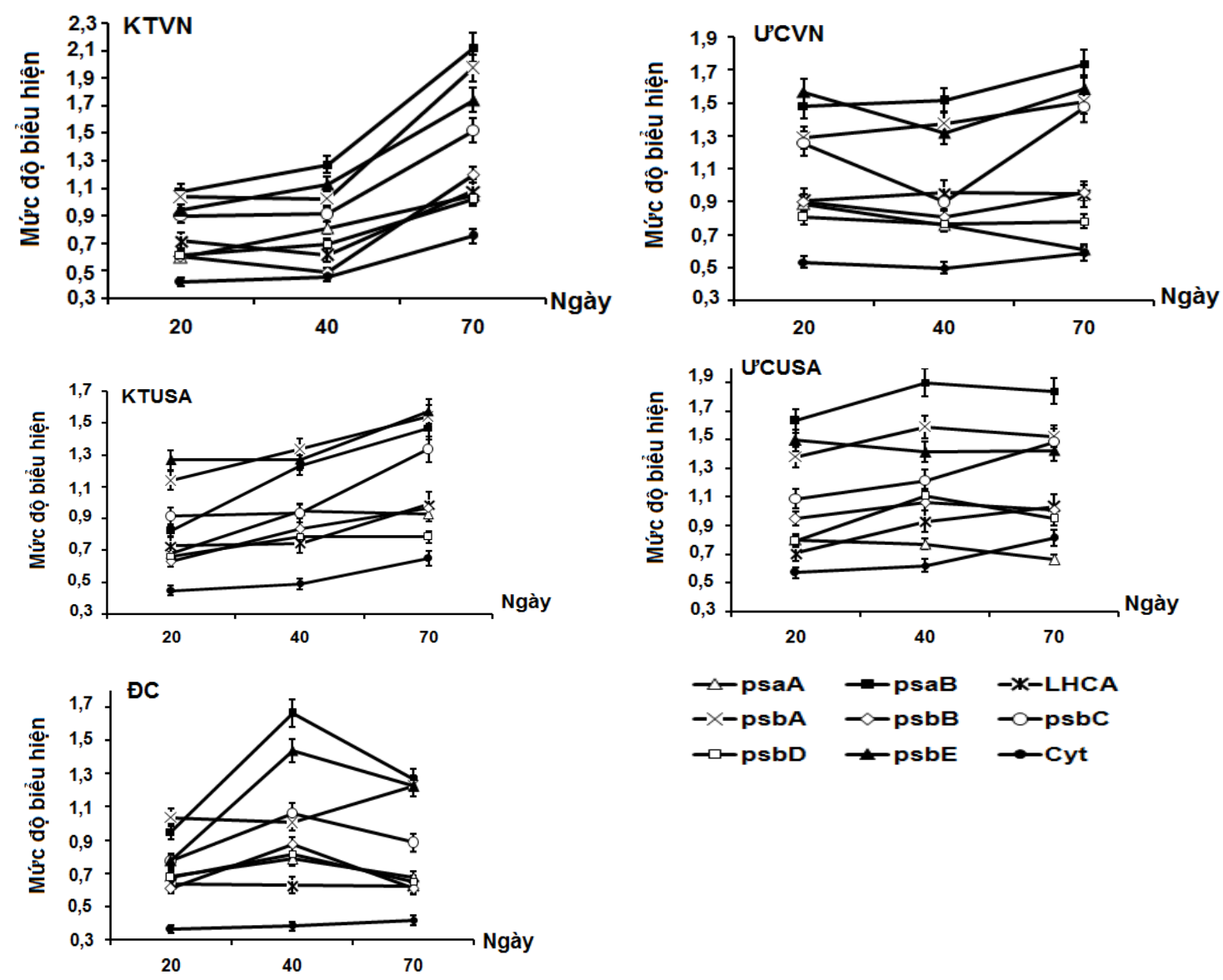

Hình 4. Mức độ biểu hiện của các gen liên quan đến hoạt tính quang hợp của cây đậu tương DT26 ở công thức khác nhau khi có và không có mặt hạt nano cobalt

\section{KẾT LUẬN}

Hạt nano cobalt hóa trị 0 với nồng độ 0,17 và $16,67 \mathrm{mg} / \mathrm{kg}$ hạt có ảnh hưởng tích cực lên hoạt động quang hợp của cây đậu tương DT26 thông qua tăng hàm lượng chlorophyll $\mathrm{a}$ và hiệu suất quang hóa cực đại, Fv/Fm. Không có sự khác biệt về hiệu quả tác động lên quang hợp giữa hạt nano cobalt do Việt Nam và Mỹ sản xuất.

Mức độ biểu hiện của các gen liên quan đến hoạt tính quang hợp của lá đậu tương cũng thay đổi theo thời gian sinh trưởng và nồng độ cobalt xử lý. So với lô đối chứng, các gen psaA, Lhca, Cytb6f (thuộc quang hệ I) và gen $p s b$ A (thuộc quang hệ II) của lô thí nghiệm có xu hướng biểu hiện tăng dần trong suốt thời gian sinh trưởng của cây. Các gen mã hóa cho các protein thuộc quang hệ II như $p s b \mathrm{~B}, p s b \mathrm{C}, p s b \mathrm{D}, p s b \mathrm{E}$ và gen $p s a \mathrm{~B}$ (thuộc quang hệ I) lại có xu hướng tăng mức độ biểu hiện ở thời điểm 20 và 70 ngày và giảm biểu hiện ở thời điểm 40 ngày. Ngay ở nồng độ xử lý cao $16,67 \mathrm{mg}$ hạt nano cobalt/kg hạt cũng 
chưa ảnh hưởng tiêu cực đến chức năng quang hợp của cây đậu tương DT26.

Lời cảm ơn: Công trình được hỗ trợ kinh phí của đề tài thuộc Hợp phần IV "Nghiên cứu co chế tác động và đánh giá an toàn sinh học của các chế phẩm nano được nghiên cứu trong dự án" có Mã số: VAST.TĐ.NANO.04/15-18, thuộc Dự án KHCN trọng điểm cấp Viện Hàn lâm KHCNVN "Nghiên cứu ứng dụng công nghệ nano trong nông nghiệp". Tác giả xin được cảm ơn GS.TS. Choon-Hwan Lee (Khoa sinh học phân tử, Đại học Quốc gia Pusan, Hàn Quốc) về những trao đồi quý báu trong việc xử lý các số liệu biểu hiện của các gen.

\section{TÀI LIỆU THAM KHẢO}

Abdul Jaleel C., Jayakumar K., Chang-Xing Z., Iqbal M., 2009. Low concentration of cobalt increases growth, biochemical constituents, mineral status and yield in Zea mays. J. Sci. Res., 1(1): 128-137.

Ahsan N., Donnart T., Nouri M. Z., Komatsu S., 2010. Tissue-specific defense and thermo-adaptive mechanisms of soybean seedlings under heat stress revealed by proteomic approach. J. Proteome. Res., 9(8): 4189-4204.

Ali B., Hayat S., Hayat Q., Ahmad A., 2010. Cobalt stress affects nitrogen metabolism, photosynthesis and antioxidant system in chickpea (Cicer arietinum L.). J. Plant Interact, 5(3): 22-231.

Barber J., Nield J., Morris E.P., Zheleva D., Hankamer B., 1997. The structure, function and dynamics of photosystem two. Physiol. Plant, 100: 817-827.

Berry J. O., Yerramsetty P., Zielinski A. M., Mure C. M., 2013. Photosynthetic gene expression in higher plants. Photosynth. Res., 117(1-3): 91-120.

Chaves M. M., Flexas J., Pinheiro C., 2009. Photosynthesis under drought and salt stress: regulation mechanisms from whole plant to cell. Ann. Bot., 103: 551-560.

Chia T. F., He J., 1999. Photosynthetic capacity in oncidium (Orchidaceae) plants after virus eradication. Environ. Exp. Bot., 42:11-16.
Collins R. N., Kinsela A. S., 2011. Pedogenic factors and measurements of the plantuptake of cobalt. Plant Soil, 339: 499-512.

DalCorso G., Manara A., Piasentin S., Furini A., 2014. Nutrient metal elements in plants. Metallomics, 6: 1770-1788.

El-Sheekh M. M., El-Naggar A. H., Osman M. E. H., El-Mazaly E., 2003. Effect of cobalt on growth, pigments and the photosynthetic electron transport in Monoraphidium minutum and Nitzchia perminuta. Braz. J. Plant Physiol., 15(3): 159-166.

Gad N., El-Moez A., Bekbayeva L. K., Karabayeva A. A., Surif M., 2013. Effect of cobalt supplement on the growth and productivity of soybean (Glycine max L. Merril). World Appl. Sci. J., 26(7): 926-933.

Jayakumar K., Abdul Jaleel C., Azooz M. M., Vijayarengan P., Gomathinayagam M., Panneerselvam R., 2009. Effect of different concentrations of Cobalt on morphological parameters and yield components of Soybean. GJMS, 4(1): 10-14.

Trần Mỹ Linh, Phạm Thị Hòe, Nguyễn Thị Thu Hiền, Lê Thị Thu Hiền, Nguyễn Hoài Châu, 2018. Đánh giá tác động của hạt nano kim loại đến quá trình nảy mầm của hạt đậu tương trong điệu kiện hạn. Báo cáo toàn văn tại Hội nghị Khoa học công nghệ sinh học toàn quốc 2018. Nxb. KHTN\&CN, H. Tr. 1539-1545.

Luciński R., Jackowski G., 2006. The structure, functions and degradation of pigment binding proteins of photosystem II. Acta Biochim. Pol., 53(4): 693-708.

Nguyễn Văn Mã, La Việt Hồng, Ong Xuân Phong, 2013. Phương pháp nghiên cứu sinh lý học thực vật. Nxb. Đại học Quốc gia Hà Nội.

Mohanty N., Vass I., Demeter S., 1989. Impairment of photosystem 2 activity at the level of secondary quinone electron acceptor in chloroplasts treated with cobalt, nickel and zinc ions. Physiol. Plant, 76: 386-390. 
Murchie E.H., Hubbart S., Peng S., Horton P., 2005. Acclimation of photosynthesis to high irradiance in rice: gene expression and interactions with leaf development. $J$. Exp. Bot., 56: 449-460.

Ngo Q. B., Dao T. H., Nguyen H. C., Tran X. T., Nguyen T. V., Khuu T. D., Huynh T. H., 2014. Effects of nanocrystalline powders $(\mathrm{Fe}, \mathrm{Co}$ and $\mathrm{Cu})$ on the germination, growth, crop yield and product quality of soybean (Vietnamese species DT-51). Adv. Nat. Sci. NanoSci. Nanotechnol., 5: $015016 \quad(7 \quad$ pp). https://doi.org/10.1088/2043$6262 / 5 / 1 / 015016$

Qiu Z., Wang L., Zhou Q., 2013. Effects of bisphenol A on growth, photosynthesis and chlorophyll fluorescence in above ground organs of soybean seedlings. Chemosphere., 90: 1274-1280.

Shao Q., Wang H., Guo H., Zhou A., Huang Y., Sun Y., Li M., 2014. Effects of shade treatments on photosynthetic characteristics, chloroplast ultrastructure and physiology of Anoectochilus roxburghii. PloS One, 9: e85996

Teixeira R.N., Ligterink W., França-Neto J.D.B., Hilhorst H.W.M, da Silva E.A.A., 2016. Gene expression profiling of the green seed problem in Soybean. BMC Plant Biology, 16(1): 37. https://doi.org.10.1186/s12870-016-0729-0

Phan Hoàng Tuấn, Hoàng Thị Lan Anh, Lưu Thị Tâm, Ngô Thị Hoài Thu, Đào Trọng Hiền, Nguyễn Hoài Châu, Đặng Diễm Hồng, 2018a. Đánh giá hiệu quả tác động của hạt nano cobalt hóa trị 0 lên sinh trưởng và các thông số quang hợp của cây đậu tương Glycine $\max (\mathrm{L})$. Merril "DT51" ở các giai đoạn sinh trưởng khác nhau. Báo cáo toàn văn tại Hội nghị Khoa học công nghệ sinh học toàn quốc 2018. Nxb. KHTN\&CN, H. Tr. 1331-1338.

Phan Hoàng Tuấn, Lưu Thị Tâm, Hoàng Thị Lan Anh, Ngô Thị Hoài Thu, Nguyễn Hoài Châu, Đặng Diễm Hồng, 2018b. Nghiên cứu ảnh hưởng của hạt nano coban dạng đơn lẻ và hỗn hợp lên sự thay đổi các thông số quang hợp và hoạt độ của enzyme chống ôxy hóa ở cây đậy tương Glycine max Merr. (DT26). Tạp chí Sinh hoc, 40(2): 333-343.

Wang B., Du Q. Z., Yang X., Zhang D., 2014. Identification and characterization of nuclear genes involved in photosynthesis in Populus. BMC Plant Biol., 14(1): 81. 